Check for updates

University of Bristol School of Community and Social Medicine, Bristol, UK

2 Institute of Population Health Sciences, Newcastle University, Newcastle upon Tyne, UK

3 Institute of Health and Wellbeing, University of Glasgow, Glasgow, UK

Correspondence to: A E Raffle angela.raffle@bristol.ac.uk

Cite this as: BMJ2020;370:m3262 http://dx.doi.org/10.1136/bmj.m3262 Published: 20 August 2020

\title{
Covid-19 mass testing programmes
}

\section{Should be modelled on successful screening programmes}

\section{Angela E Raffle, ${ }^{1}$ Allyson M Pollock, ${ }^{2}$ Louisa Harding-Edgar ${ }^{3}$}

Mass testing programmes for covid-19 should be drawing on the UK's considerable track record in delivering high quality screening programmes for communicable and non-communicable disease..$^{1-4}$ Testing of people with no signs or symptoms has important differences from testing that aims to reach a diagnosis when someone has sought help for a problem. In diagnostic testing, the clinician-patient relationship usually affords a degree of judgment and safety. The clinician knows the person, gives explanation and advice, explains the limitations of tests, and obtains implicit or explicit consent.

For tests performed outside this context-such as screening, surveillance, or case finding-these safeguards are missing and the pitfalls are numerous. The aim is risk reduction, with a constant need to balance benefit, harm, and affordability. The common feature is the offer or mandate of tests for a population or group. ${ }^{5}$ Uses are numerous and include epidemiological research, communicable disease control, protection of others (such as criminal record checks for workers), commercial gain (such as direct-to-consumer genetic tests), and reducing health risks as in the 11 national screening programmes (antenatal, newborn, young person, and adult screening) offered in the UK, including screening pregnant women for HIV, hepatitis B, and syphilis.

\section{Clear case definition}

Mass testing for covid-19 aims to find people with active infection who are asymptomatic or presymptomatic so that quarantine, and rapid finding and testing of close contacts, can interrupt spread. ${ }^{67}$ Such an approach needs speed and clarity on what constitutes a case. Cases are currently defined as someone in whom polymerase chain reaction testing detects viral RNA, whether active or not. This, and open access testing for anyone who self-refers, mean that "cases" inevitably include people with past infections and those with active infection who are identified too late to make much difference to onward transmission.

A good test in a diagnostic setting can be less good when used for screening. A given test, with a defined cut-off has a constant sensitivity (how accurately it identifies cases) and specificity (how accurately it identifies non-cases). However, the predictive values (what proportion of people with positive test results genuinely have active infection, what proportion of people with negative results are genuinely free from active infection) are influenced by the prevalence of active infection in the group being tested. All mass testing produces false alarms and missed cases. ${ }^{8}$ Testing by unskilled staff, self-testing, and variable quality of testing kits ${ }^{9}$ compound the inaccuracies. The predictive values of a programme of testing, relating to ability to identify active infections in actual practice, are distinct from laboratory measures of test quality. These "field" predictive values need to be quantified and clearly explained.

\section{Strong systems}

A key lesson from screening is that the entire system must be well coordinated, have quality assurance built in for each element, and be backed by the right information technology. Without a good system the benefits are unlikely to be realised, and the main outcomes will be harms from unwarranted intervention, confusion, mistrust, and diversion of laboratory and other resources away from more beneficial activities. The system must ensure that testing is accessible, trusted, and tailored to all sections of society (especially ethnic minority groups and those at disadvantage)-otherwise those who most need testing will not be reached. Local primary care and public health teams must be involved in supporting participants, ensuring that test results are understood and can be acted on.

Data for the programme need careful analysis and presentation. For covid-19, this means-at the very least-separating diagnostic tests from screening tests, recording clearly the indications for testing (such as employment, contacts of known case, community versus institutional residence), and using area based denominators. If denominators are ignored, apparent spikes in cases caused by ascertainment bias could trigger unhelpful lockdowns.

Ethical standards require that participants be informed about the purpose, limitations, and uncertainties, whether testing is an offer or is mandatory, and how their data will be used. ${ }^{10}$ Information about SARS-CoV-2 from epidemiological research is essential, but boundaries between research and service provision should not be blurred. In the early 2oth century, collection of epidemiological data was a hidden driving force behind poorly evidenced screening and led to lasting confusion about the purpose and value of testing well people. ${ }^{4}$

Mass testing for covid-19 is a vast undertaking. It needs clear purpose and policy based on best available evidence, uniform case definitions, and consistent testing standards nationwide. It needs clarity about who is eligible for testing and who is responsible for communicating, interpreting, and acting on test results. Systematic coordinated delivery using the experience, community connections, and knowledge of local primary care, public health, and laboratory services is essential. ${ }^{11}$ To be effective, testing needs to be accessible even to the most 
disadvantaged people in society, and those tested need to receive support, information, and advice from experienced practitioners. Otherwise the system will be chaotic, wasteful, ineffective, and harmful.

Competing interests: We have read and understood BMJ policy on declaration of interests and declare that AER has worked for the UK national screening programmes since their inception in 1996. AMP is a member of Independent SAGE. The views expressed here are their own.

Provenance and peer review: Commissioned; not externally peer reviewed.

1 Association of Directors of Public Health. Public health leadership multi-agency capability: guiding principles for effective management of covid-19 at local level. 2020. https://www.adph.org.uk/wpcontent/uploads/2020/06/Guiding-Principles-for-Making-Outbreak-Management-Work-Final.pdf

2 Hawker J, Begg N, Reintjes R, etal. Communicable disease control and health protection handbook. 4th ed. Wiley Blackwell, 2019doi: 10.1002/9781119328070.

3 Raffle AE, Taylor-Phillips S. Test, test, test; lessons learned from experience with mass screening programmes. Advice note for Independent SAGE, 5 June 2020. https://research-information.bris.ac.uk/ws/portalfiles/portal/245953726/ISAGE_ad

vice_note_5_june_2020fv_lessons_from_screening_programmes.pdf

4 Raffle AE, Mackie A, Gray JAM. Screening; evidence and practice. 2nd ed. Oxford University Press, 2019doi: 10.1093/med/9780198805984.001.0001.

5 Speechley M, Kunnilathu A, Aluckal E, Balakrishna MS, Mathew B, George EK. Screening in public health and clinical care: similarities and differences in definitions, types, and aims-a systematic review. J Clin Diagn Res 2017;11:LE01-04. doi: 10.7860/JCDR/2017/24811.9419 pmid: 28511418

6 Rough E. Coronavirus: testing for covid-19. House of Commons briefing paper. 5 Aug 2020. https://assets.publishing.service.gov.uk/government/uploads/system/uploads/attachment_data/file/895843/S0519_Impact_of_false_positives_and_negatives.pdf

7 Buitrago-Garcia DC, Egli-Gany D, Counotte MJ, et al. Asymptomatic SARS-CoV-2 infections: a living systematic review and meta-analysis. medRxiv 2020.04.25.20079103. [Preprint.] https://www.medrxiv.org/content/10.1101/2020.04.25.20079103v3

8 Mayers C, Baker K. Impact of false-positives in the UK's COVID-19 testing programmes. Paper prepared for the Government Office of Science, 2 Jun 2020. https://assets.publishing.service.gov.uk/government/uploads/system/uploads/attachment_data/file/895843/S0519_Impact_of_false_positives_and_negatives.pdf

9 Coronavirus: Randox recalls up to 750000 test kits over safety concerns. BBC News 2020 Aug 8. https://www.bbc.co.uk/news/health-53705229

10 General Medical Council. Consent: patients and doctors making decisions together. GMC, 2008.

11 Martin J, Royal College of Pathologists' Trustees Board. Covid-19 testing: a national strategy. 2020 https:/www.rcpath.org/profession/on-the-agenda/covid-19-testing-a-national-strategy.htm

This article is made freely available for use in accordance with BMJ's website terms and conditions for the duration of the covid-19 pandemic or until otherwise determined by BMJ. You may use, download and print the article for any lawful, non-commercial purpose (including text and data mining) provided that all copyright notices and trade marks are retained. 